\title{
Gel express: a novel frugal method quantifies gene relative expression in conventional RT-PCR
}

\author{
Mohamed Hazman * ${ }^{*}$
}

\begin{abstract}
Background: Real-time PCR system is a valuable scientific mainstream needed for quantifying specific gene expression. Nevertheless, compared with conventional PCR, the real-time PCR system is extremely expensive and not affordable for limited or mid-budget research laboratories. Here, a novel, doable and low-cost recipe (referred to as gel express) is developed to quantify gene expression using conventional RT-PCR assay. The novelty of the gel express method is based on replacing crossing point (CP) values with integrated density (IntDen) values of PCR amplicon bands in real-time PCR regular mathematical formulas.

Results: In this work, gene expression profiles of two different rice stress-marker genes (OsCYP94C2a and OsLOX8) were quantified in response to mechanical wounding at different time points $(0,30,60$, and $150 \mathrm{~min})$. In the gel express method, the free software Image J was employed to measure integrated density (IntDen) values of PCR amplicon bands in agarose gel images. IntDen values were then used instead of crossing point (CP) values according to the following modified formula: $\left[E^{\text {IntDen(ref) }} / E^{\text {IntDen(target) }}\right]_{\text {sample }} \div\left[E^{\text {IntDen(ref) }} / E^{\text {IntDen(target) }}\right]_{\text {control. }}$ Gene relative expression profiles (dynamic expression pattern) quantified by gel express method in both genes were highly comparable with realtime RT-PCR. R ${ }^{2}$ values were 0.9976 and 0.9975 in OsCYP94C2a and OsLOX, respectively. PCR amplification efficiency (E) for all studied genes could be calculated depending on IntDen values through experimentally designed calibration curves. PCR amplification efficiencies with all studied genes obtained by gel express were all in the accepted range. For better-visualized PCR amplicons thus detectable biological effects between treatments, the number of PCR cycles applied in gel express method (IntCyc) was experimentally estimated to be 29 cycles.
\end{abstract}

Conclusions: Gel express is a novel, cost-effective and feasible recipe for quantifying gene relative expression in conventional RT-PCR. The expression pattern quantified by gel express is highly comparable and fits the expression data revealed by the used real-time PCR system.

Keywords: Gel express, Integrated density, Crossing point, ImageJ, Conventional RT-PCR

\section{Background}

Quantifying gene expression is an important molecular parameter for understanding how living organisms respond to different environmental or biological stress forms. It is also required to monitor fine molecular changes during developmental growth and differentiation [1]. There are main four methods for quantifying specific gene expression: Northern blotting and in situ

*Correspondence: yousof_3@hotmail.com

Agricultural Genetic Engineering Research Institute (AGERI), Agricultural

Research Center, 9 Gamma St, Giza 12619, Egypt hybridization [2], RNase protection assays [3, 4], and the reverse transcription-polymerase chain reaction (RTPCR) [5]. However, for transcriptomic broader scope, microarray and next-generation sequencing (RNA-seq) are the two most well-known adopted strategies [6]. The quantification of mRNA for a specific gene through conventional RT-PCR is the most popular gene expression method, particularly for low or rare expression level genes [7]. Nevertheless, the technique notoriously provides mere qualitative data and thus needs to be further quantified for more reliable conclusions [8]. 
The emergence of the fluorescent-dependent PCR techniques (commonly known as real-time PCR or quantitative PCR) using SYBR green chemistry greatly enhanced the quantification of mRNA abundance of specific genes, i.e., genes with known sequences. Cleverly, real-time PCR could combine amplification and analysis steps, thus eliminating the need for post-PCR processing as agarose gel electrophoresis and subsequent imaging systems [9]. Importantly, it is required to confirm candidate gene expression to validate RNA-seq data and reduce errors of wide-range sequencing platforms [10]. Nevertheless, the real-time PCR system is extremely expensive and not accessible for a wide range of research laboratories. Most of the costs come from the real-time PCR instrument itself with a price possibly exceeding 10 times more than any conventional PCR machine. Furthermore, there are some additional essential running costs such as kits and special disposable (PCR tubes/plates with special lids) which, if not fairly provided, the system could be paused.

Four main tasks should be achieved by using real-time PCR systems: gene relative expression, DNA copy number, viral load, and allelic discrimination [11]. The scope of this work is to provide a frugal approach for molecular biology research laboratories interested in reliable gene relative expression quantitative studies but have no access to operative real-time PCR systems. Therefore, the "gel express" approach was developed to facilitate the quantification of mRNA abundance of specific genes using reverse transcription conventional PCR (RT-PCR). Compared with real-time RT-PCR, gel express showed highly comparable dynamic expression patterns. In this work, the adaptability of the new recipe (referred here as gel express) as a reliable method for quantifying gene relative expression using conventional RT-PCR was discussed.

\section{Methods}

\subsection{Plant materials, growth and stress conditions}

Seeds of Egyptian rice cultivar Giza 177 kernels (provided by Rice Research and Training Center (RRTC), Agricultural Research Center (ARC), Giza, Egypt)were manually de-husked and surface disinfected using 70\% ethanol for 1 min then rinsed in 50\% chlorox for 30 min with gentle shaking. The seeds were subsequently washed 5 times with sterile distilled water then air-dried under the hood on sterile filter paper for $10 \mathrm{~min}$. The seeds were sowed on wet sterile cotton in sterile baby food jars and incubated at room temperature for 10 days till the second leaf emerged [12]. The stress of choice in this study was the mechanical wounding damage, which was applied using clean metal forceps on second leaves. Wounded leaves were harvested after 0 (control), 30, 60, and $150 \mathrm{~min}$ and immediately kept in liquid nitrogen then stored at $-80{ }^{\circ} \mathrm{C}$ for subsequent molecular analysis.

\subsection{Total RNA isolation and first-strand cDNA synthesis}

Total RNA was isolated from the second leaf of control (0 min) and wounded rice plants (30, 60, and $150 \mathrm{~min})$ using Direct-zol RNA Miniprep (Zymo Research, USA) according to manufacturer's instructions which included in-column DNase treatment. The concentration and purity of all RNA samples were quantified through NanoDrop $^{\circledR}$ spectrophotometer (Thermo Fisher Scientific, USA) at $260 \mathrm{~nm}$ and $260 / 280 \mathrm{~nm}$, respectively. The cDNA was synthesized from $2000 \mathrm{ng}$ total RNA as a template using the RevertAid First-Strand cDNA synthesis kit according to manufacturer protocol (Thermo Scientific, Lithuania).

\subsection{Monitoring PCR amplification steps using gel express and real-time PCR}

20 ng cDNA for each sample ( $1 \mu$ l of 1:5 diluted cDNA) was used as the DNA template in either PCR method. For real-time PCR, HERA SYBR ${ }^{\circledR}$ Green RT-qPCR kit (Willofort, UK) was used according to manufacturer default protocol. The quantitative PCR system used in this study was QuantStudio $^{\mathrm{TM}} 3$ Real-Time PCR System (Thermo Fisher Scientific, USA). The amplification program was as follows: $95{ }^{\circ} \mathrm{C}$ for $2 \mathrm{~min}$, and 40 cycles of $95^{\circ} \mathrm{C}$ for $15 \mathrm{~s}$, $60{ }^{\circ} \mathrm{C}$ for $30 \mathrm{~s}$ and $72{ }^{\circ} \mathrm{C}$ for $1 \mathrm{~min}$.

In the case of gel express, conventional PCR reaction was performed using amar OnePCR master mix (GeneDirex, Taiwan) by applying manufacturer protocol. The thermal cycles program used with conventional PCR machine (T100 ${ }^{\mathrm{TM}}$ Thermal Cycler, Biorad, USA) was as follows: $94{ }^{\circ} \mathrm{C}$ for $2 \mathrm{~min}$, cycles\# (individually adjusted, see below) of $94{ }^{\circ} \mathrm{C} 30 \mathrm{~s}, 60^{\circ} \mathrm{C}$ for $30 \mathrm{~s}$ and $72{ }^{\circ} \mathrm{C}$ for $1 \mathrm{~min}$, and the final extension was at $72{ }^{\circ} \mathrm{C}$ for $5 \mathrm{~min}$. The experiment was designed that each conventional PCR reaction represents a certain desired number of cycles (cycles\#). The investigated cycles\# were 18, 20, 22, 24, 26, 28, 30, 32, and 34 . Each number of cycles was independently represented by an individual PCR tube for each gene. When the PCR machine informed the end of each investigated number of cycles, the lid of the PCR machine was manually opened and the relevant tube was transferred from the PCR machine heated block into a pre-chilled metal rack for at least $10 \mathrm{~min}$ to stop the reaction. The investigated genes in either PCR system are OsCYP94C2a (jasmonates turnover), OsLOX8 that encodes lipoxygenase 8 (jasmonates biosynthesis), and rice $\beta$-actin as reference gene. The sequences of forward and reverse primers are listed in Table 1. 
Table 1 The sequences of forward and reverse primers for investigated genes

\begin{tabular}{|c|c|c|c|c|}
\hline Gene Name & Gene Function & Accession number (MSU) & Forward ( $5^{\prime}$ to $3^{\prime}$ prime) & Reverse ( $5^{\prime}$ to $3^{\prime}$ prime) \\
\hline OsCYP94C2a & Jasmonates turnover & LOC_Os11g05380 & GAAGACTTCACTTCTACTGCAACA & ACGAGGAAACCATGACGAAC \\
\hline $\begin{array}{l}\text { OsLOX8 (Jas- } \\
\text { monates biosyn- } \\
\text { thesis) }\end{array}$ & Lipoxygenase & LOC_Os08g39850 & CGTTCATGTCATCATGTGTGT & GCACCATTCAATGTAAATGCTATC \\
\hline Actin & Actin (ref) & LOC_Os10g36650 & ATGCCATTCTTCTCCGTCTT & GCTCCTGCTCGTAGTC \\
\hline
\end{tabular}

The PCR product of each sample was electrophoresed through $1.5 \%$ agarose gel stained with a standard concentration of Ethidium Bromide $(1 \mu \mathrm{g} / \mathrm{ml})$ and visualized by UV transilluminator. The agarose gel was then photographed by the Gel Documentation system (Biorad, USA) and the raw agarose gel images (blackish background/ whitish bands) were saved for subsequent image analysis steps. Gel express protocol was applied to measure the integrated density (IntDen) value of each PCR amplicon using ImageJ software but with raw agarose gel images. Subsequently, IntDen values were plotted against each cycle number for estimating IntCyc or integrated cycle. IntCyc value refers here to the number of cycles recommended as an end-point cycle in the gel express method. It is assumed that IntCyc value is preferred to represent the middle of the exponential phase in the PCR amplification steps plot.

\subsection{Determining conventional and real-time PCR amplification efficiencies $(E)$}

The cDNA amount in every PCR reaction was $2 \mu \mathrm{l}$ representing the different quantities of cDNA serially diluted in 1:2 ratio with total starting cDNA quantity of 200, 100, $50,25,12.5,6.125$, and 3.0625 ng per PCR reaction. Realtime and conventional PCR master mixes were prepared as previously mentioned. In gel express, PCR reaction was programmed to end after 25 cycles in OsCYP94C2a, and 33 cycles in OsLOX8. The reference gene actin was independently examined with each target gene according to the number of cycles. The PCR product of each sample was electrophoresed through $1.5 \%$ agarose gel stained with a standard concentration of Ethidium Bromide $(1 \mu \mathrm{g} / \mathrm{ml})$ and visualized by UV transilluminator. The agarose gel was then photographed by the Gel Documentation system (Biorad, USA), and the color of the obtained raw agarose gel images was inverted from blackish background/whitish band to be whitish background/blackish bands. The IntDen value of each PCR amplicon band was determined using ImageJ (see detailed protocol below) then plotted against the $\log _{2}$ of each corresponding starting cDNA quantity. In real-time PCR, each crossing point $(\mathrm{CP})$ value was plotted against the corresponding $\log _{2}$ starting cDNA quantity. PCR amplification efficiency
(E) was calculated according to [13]: $E=d^{[-1 / \text { slope }]}$ where $\mathrm{d}$ is the dilution factor of cDNA quantities (here equals $2)$, so the formula is $E=2^{[-1 / \text { slope }]}$. Efficiency percentage $=(E-1) * 100$.

\subsection{Relative gene expression pattern quantification by gel express and real-time PCR}

Conventional and real-time PCR methods were performed using $20 \mathrm{ng}$ cDNA for each sample as the DNA template. The setting up of both real-time and conventional PCR reactions was mentioned earlier in this chapter. The thermal cycler program for conventional PCR machine was as follows: $94{ }^{\circ} \mathrm{C}$ for 2 min, 29 cycles (IntCyc) of $94{ }^{\circ} \mathrm{C} 30 \mathrm{~s}, 60^{\circ} \mathrm{C}$ for $30 \mathrm{~s}$ and $72^{\circ} \mathrm{C}$ for $1 \mathrm{~min}$, and the final extension was at $72{ }^{\circ} \mathrm{C}$ for $5 \mathrm{~min}$. PCR reaction was stopped by holding the tubes at $4{ }^{\circ} \mathrm{C}$ for at least $10 \mathrm{~min}$. The PCR product of each sample was electrophoresed through $1.5 \%$ agarose gel stained with a standard concentration of Ethidium Bromide $(1 \mu \mathrm{g} / \mathrm{ml})$ and visualized by UV transilluminator. The agarose gel was then photographed by the Gel Documentation system (Biorad, USA). Raw agarose gel images color pattern (blackish background/whitish bands) was directly inverted using Gel Doc system software to be whitish background/blackish bands, then saved for subsequent image processing work.

\subsection{Measuring integrated density (IntDen) values in inverted agarose gel images}

Using previously saved color-inverted agarose gel images, integrated density (IntDen) values were measured using ImageJ software as follows: 1) Converting image to grayscale: Image - Type -8 -bit. 2) Image scale: Straight line - Mark the width of one agarose well - Analyze - Set Scale - input the known length and unit (0.5 cm in this study). 3) Measuring Integrated Density (IntDen) values: Rectangle mark the desired band area - Press " $\mathrm{t}$ " to add it to ROI - click measure after adding all marked samples. Save the raw data table as CSV file and then re-save it as excel. It is important to make sure that the rectangle area is the same with all measured band samples. The measurements should 
be taken for target and reference genes that should be loaded together within the same agarose gel. During documentation of the agarose gel for taking images, imaging conditions should be the same for all agarose gels, i.e., zoom degree, light, contrast, exposure, etc.

\subsection{Calculating relative gene expression using gel express method and real-time PCR}

Gene relative expression was quantified by real-time PCR according to a mathematical model developed by [13] as follows:

$$
\left[E^{\mathrm{CP}(\text { ref })} / E^{\mathrm{CP}(\text { target })}\right]_{\text {sample }} \div\left[E^{\mathrm{CP}(\text { ref })} / E^{\mathrm{CP}(\text { target })}\right]_{\text {control }}
$$

In gel express method, integrated densities (IntDen) replaced CP values in previous formula with IntDen values according to the following formula:

$$
\begin{aligned}
& {\left[E^{\text {IntDen(ref) }} / E^{\text {IntDen(target) }}\right]_{\text {sample }}} \\
& \div\left[E^{\text {IntDen(ref) }} / E^{\text {IntDen(target) }}\right]_{\text {control }}
\end{aligned}
$$

\section{Results}

\subsection{Gel express monitors PCR amplification steps} and estimates integrated cycle (IntCyc)

The integrated density of each PCR amplicon band visualized in raw agarose gel images (black background/white bands, Fig. 1b) was measured using Image $J$ and then plotted against each corresponding cycle (Fig. 1a). The PCR amplicon band was initially detectable to eyes after 22 cycles in actin, 24 cycles in OsCYP94C2a, and 28 cycles in OsLOX8 (Fig. 1b). The integrated cycle (IntCyc) is estimated as 29 cycles (dashed red line, Fig. 1a); it should be applied for all investigated genes (target and reference). The term integrated cycle (IntCyc) in this study refers to the number of cycles that is recommended for the gel express method as an end-point PCR-dependent method. It is assumed to be at the middle of the exponential phase as shown by the red dashed line in Fig. 1a. The amplification plot of the three studied genes was revealed by QuantStudio ${ }^{\mathrm{TM}} 3$ Real-Time PCR System (Thermo Fisher Scientific, USA) and presented in Fig. 1c. The amplification plot of gel express

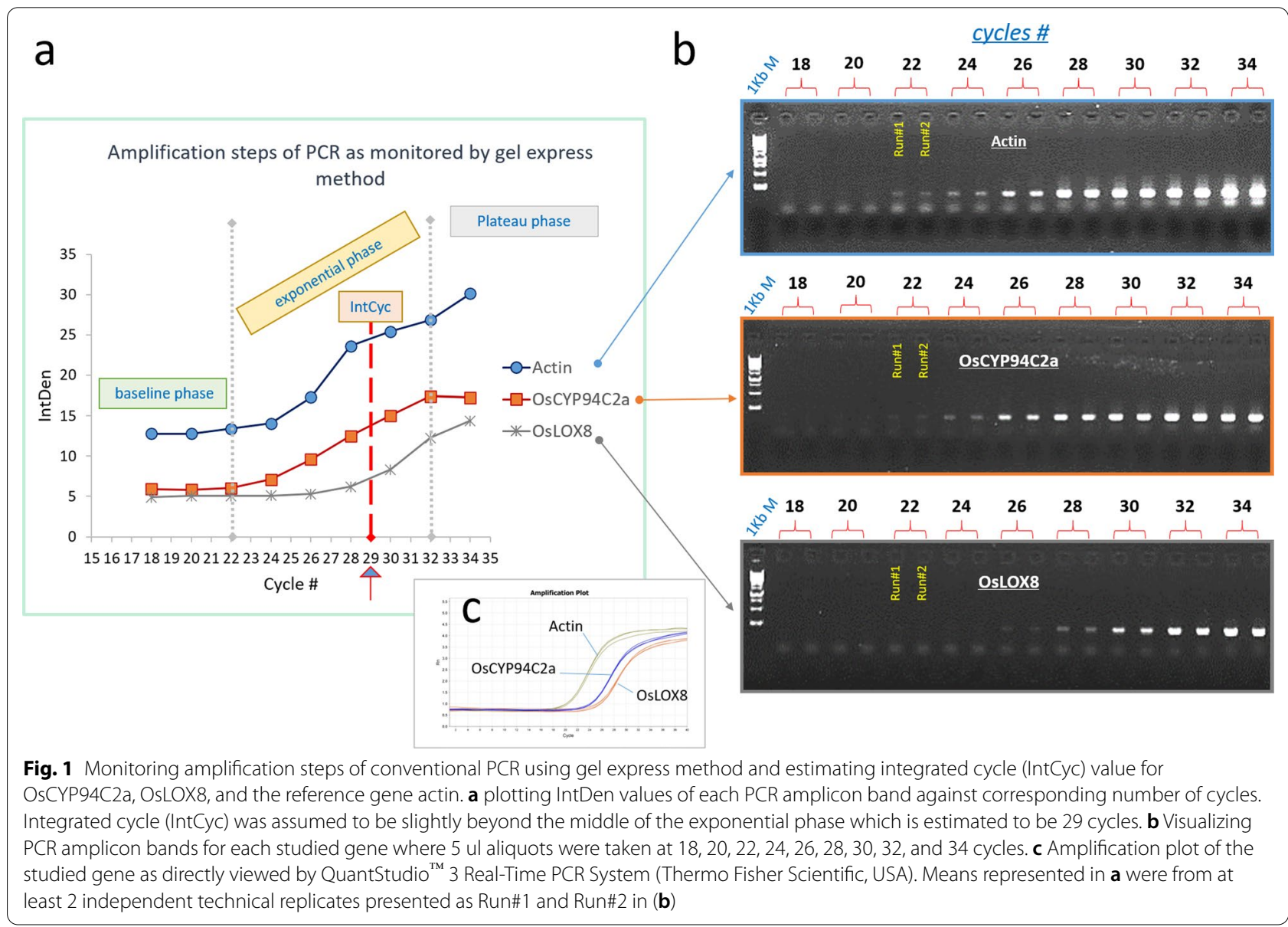


and real-time PCR were in accordance; both show actin as the most expressed gene followed by OsCYP94C2a then OsLOX8 (Fig. 1a, c).

\subsection{Gel express could determine PCR amplification efficiency $(E)$}

The PCR amplification efficiency $(E)$ with each investigated gene was determined by both gel express method and real-time PCR (Fig. 2). The $E$ values were calculated based on the equation: $E=d^{[-1 / \text { slope }]}$, where $\mathrm{d}$ is the used dilution factor of cDNA amounts (here $d=2$ ), and slope represents the coefficient of PCR efficiency plot for each used primer. IntDen and CP values were separately plotted against the logarithmic (base 2) values of the cDNA quantities. The real-time PCR efficiency plot revealed that $E$ values were $2.3,2.14$, and 2.2 for actin, OsCYP94C2a, and OsLOX8, respectively (Fig. 2c). PCR amplification efficiency with the reference gene actin was independently calculated with each target gene under the applied number of cycles. PCR efficiency $(E)$ in OsCYP94C2a and actin genes after 25 cycles were 1.73 and 1.89, respectively (Fig. 2a). OsLOX8 expression level was much lower than OsCYP94C2a after 25 cycles (data not shown). Therefore, $E$ values for OsLOX8 and actin gene were calculated after 33 cycles and found to be1.7 and 2.17 , respectively (Fig. 2b). The PCR amplicon bands processed by gel express method for producing corresponding calibration curves are presented in Fig. 2 d.

\subsection{Gene dynamic expression displayed by gel express is highly comparable to real-time PCR}

The expression profiles of OsCYP94C2a and OsLOX8 were quantified in response to wounding stress after 0 , 30, 60, and 150 min (Figs. 3 and 4). Real-time PCR and gel express methods showed that OsCYP94C2a was strongly upregulated in response to wounding stress
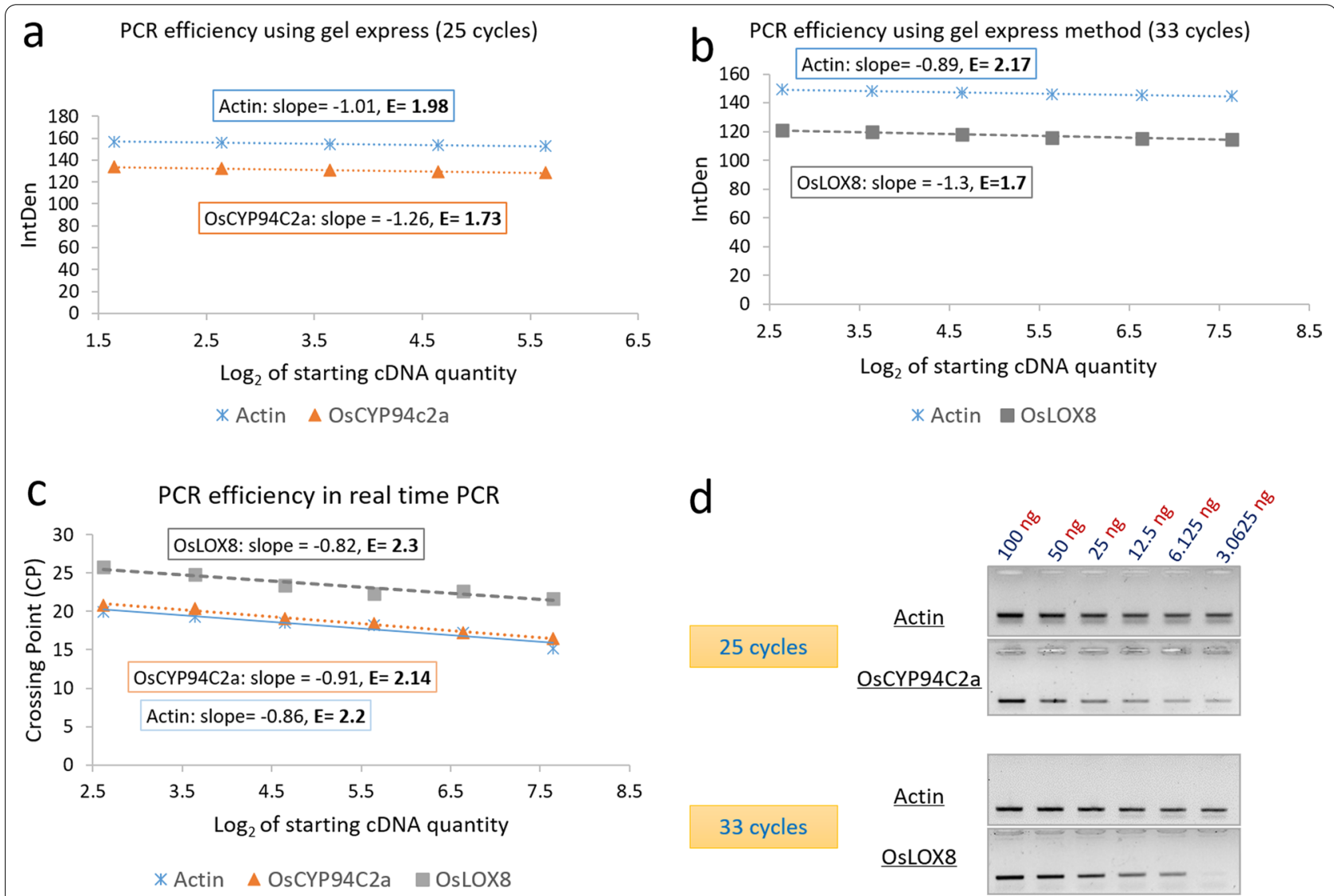

Fig. 2 PCR amplification efficiency determination using gel express and real-time PCR methods. a Integrated densities (IntDen) values were plotted against the $\log _{2}$ values of initial cDNA quantities for the target gene OsCYP94c2a and reference gene actin after 25 cycles of amplification. b Integrated densities (IntDen) values were plotted against the $\log _{2}$ values of initial cDNA quantities for the target gene OsLOX8 and its reference gene actin after 33 cycles of amplification. c crossing points (CP) values were plotted against $\log _{2}$ values of initial cDNA quantities for target genes OsCYP94C2a and OsLOX8, and the reference gene actin. For $\mathbf{a}, \mathbf{b}$, and $\mathbf{c}$, slopes were determined then used to calculate PCR efficiency $E$ values according to the formula $E=2^{[-1 / \text { slope] }}$ [13]. Means in $\mathbf{a}, \mathbf{b}$ and $\mathbf{c}$ represented at least 3 independent technical replicates. $\mathbf{d}$ Representative agarose gel electrophoresis (image with inverted color) used to plot (a) and (b) 

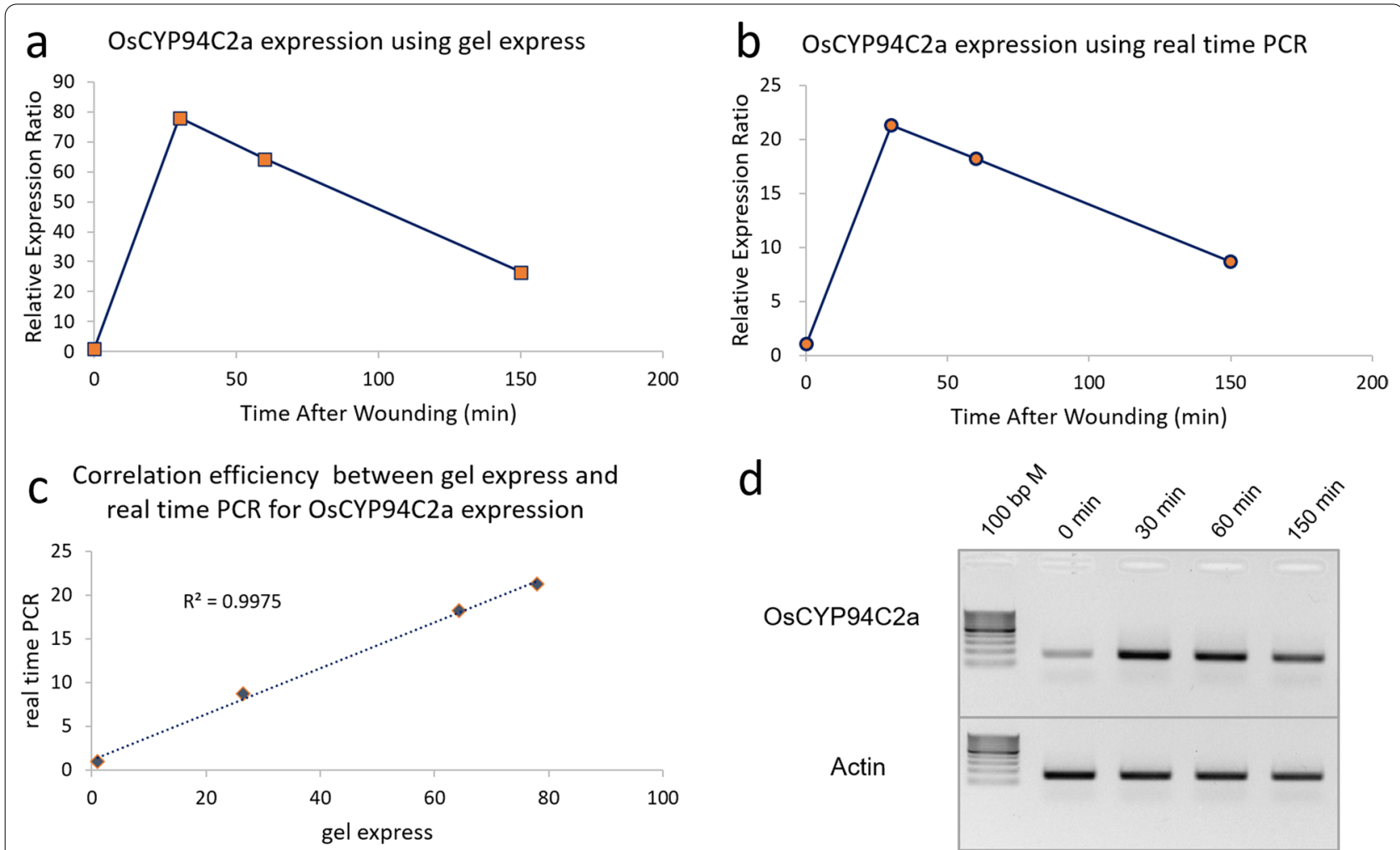

Fig. 3 Dynamic gene expression profile for the target gene OsCYP94C2a using gel express (a) and real-time PCR method (b) at four different time point after wounding: 0 (control), 30, 60 and 150 min. The expression pattern quantified by gel express method was associated with real-time PCR through regression analysis (c), $R^{2}$ equals to 0.9975 . $\mathbf{d}$ Agarose gel electrophoresis (inverted color images) showing the migration of PCR product of OsCYP94C2a and actin fragments after 29 cycles of amplification used to plot (a)

after $30 \mathrm{~min}$ and then the expression ratio was gradually attenuated after 60 and 150 min from wounding (Fig. 3a, b). The calculated relative ratio of expression was 21.25 , 18.23, and 8.66 in the real-time PCR method compared to $78,64.3$, and 26.5 with gel express. Although the values of relative gene expression were not the same in gel express compared to the real-time PCR method at each time point, the correlation between the two methods was high as indicated by $\mathrm{R}^{2}$ that equals 0.9975 (Fig. 3c). Figure 3d illustrates the visualized OsCYP94c2a PCR amplicon bands in a representative agarose gel image with inverted colors (similar to a photographic negative) used by gel express method for gene expression quantification.

The expression level of OsLOX8 was also investigated in rice seedlings in response to wounding damage (Fig. 4). Unlike OsCYP94C2a that was expressed in a fluctuating style, OsLOX8 was expressed in an accumulative pattern, i.e., becomes higher over time following the wounding event. The expression ratios in real-time PCR were $4.45,10.31$, and 24.97 after 30,60 , and $150 \mathrm{~min}$, respectively (Fig. 4b), while expression ratios produced by the gel express method were 2.13, 5.4, and 13.1 (Fig. 4a). Dynamic pattern expression of OsLOX8 gene was constant in both PCR methods where $\mathrm{R}^{2}=0.9976$ (Fig. 4c). A representative agarose gel image for OsLOX8 PCR-specific amplicon bands that have been analyzed by gel express for determining relative gene expression is presented in Fig. 4d. The protocol of gel express method by describing photographed steps for measuring integrated density (IntDen) of each PCR amplicon band is illustrated in Fig. 5.

\section{Discussion}

In this work, gel express recipe was developed to quantify the relative expression ratios of specific genes using conventional RT-PCR, the most cost-effective universal system for amplifying even low amounts of mRNA [14]. Several methods were already developed to analyze agarose gel images for variable purposes as comparative molecular weight detection and drawing phylogenetic trees $[15,16]$. Intensities of PCR amplicon bands visualized in raw agarose gel images (blackish background/ whitish bands) were directly used to represent mere direct ratios of intensities $[17,18]$. For doing so, intensities of target gene bands in raw agarose gel images were divided by reference gene bands intensities to calculate 

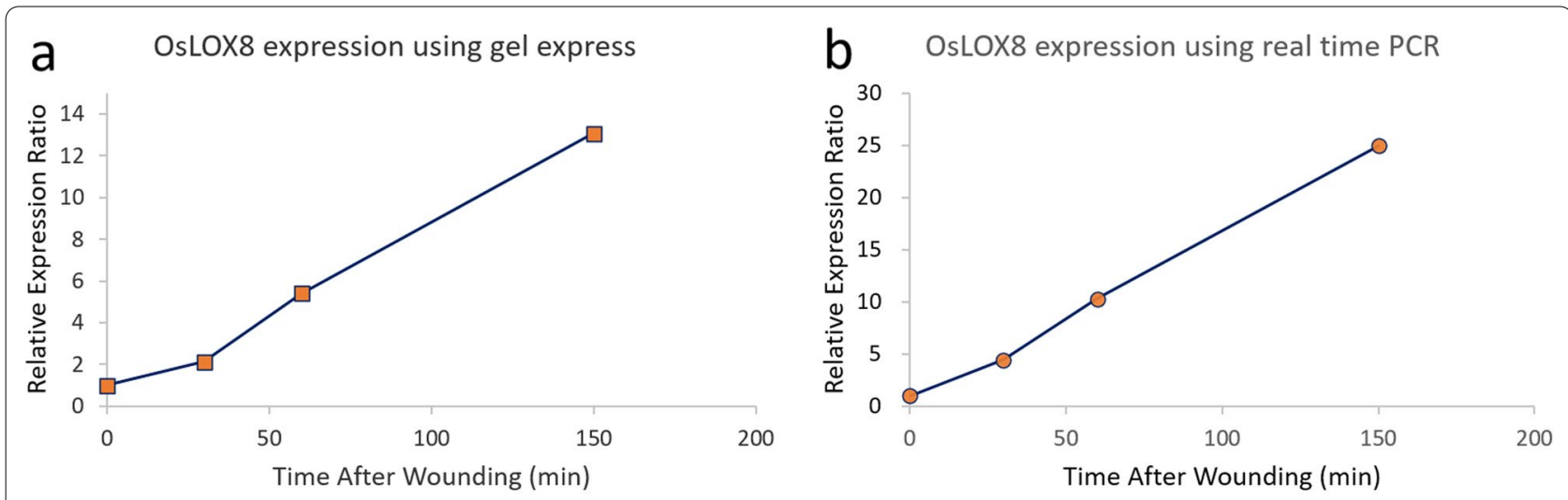

\section{Correlation Efficiency between gel express and}

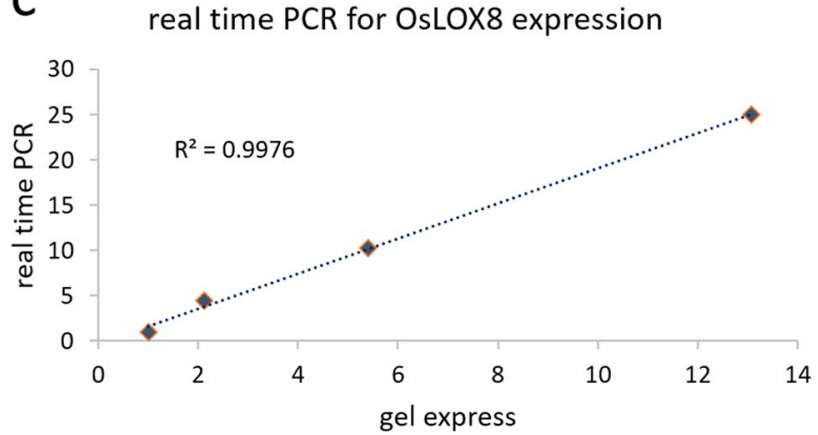

d

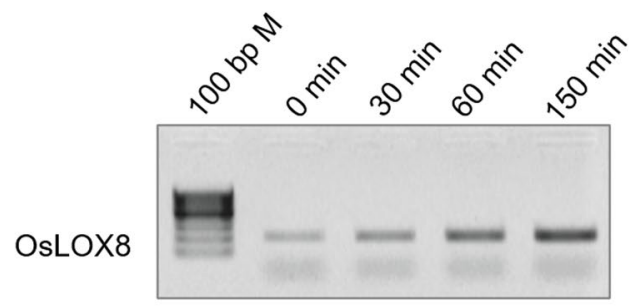

Fig. 4 Dynamic gene expression profile for the target gene OsLOX8 using gel express (a) and real-time method (b) at four different time point after wounding: 0 (control), 30,60 and $150 \mathrm{~min}$. The expression pattern quantified by gel express method was associated with time PCR output data through regression analysis (c), $R^{2}$ equal to 0.9976. $\mathbf{d}$ Agarose gel electrophoresis (inverted color images) showing the migration of RT-PCR product of actin and OsLOX8 fragments after 29 cycles of amplification

the semi-quantitative relative transcripts abundance [19, 20]. Gel express, on the other hand, is a quantification tool encompassing analyzing agarose gel images to determine PCR amplicon bands integrated density (IntDen). Subsequently, IntDen values are used directly instead of crossing point $(\mathrm{CP})$ determinant in real-time PCR equations for quantifying gene relative expression as follows:

$$
\begin{aligned}
& {\left[E^{\text {IntDen(ref) }} / E^{\text {IntDen(target) }}\right]_{\text {sample }}} \\
& \div\left[E^{\text {IntDen(ref) }} / E^{\text {IntDen(target) }}\right]_{\text {control }}
\end{aligned}
$$

Integrated density (IntDen) is the sum of the values of the pixels in the whole image or selected part of it. When an agarose gel inverted-color image is converted to grayscale by 8-bite option using ImageJ software, this creates 256 values: 0 for pure black, 256 for pure white, and 254 Gray values steps in between (https:// imagej.nih.gov/ij/docs/menus/analyze.html). Indeed, in inverted agarose gel images, IntDen of highly expressed OsCYP94C2a sample at $30 \mathrm{~min}$ after wounding was 69.3 arbitrary units (AU) while it was 76.4 AU with the low expressed control not-wounded sample (Fig. 5).
Provided identical rectangle area for all selected bands using Image (Fig. 5d), the higher expressed sample (69.3 $\mathrm{AU})$ with more blackish gray pixels produced lower IntDen values. On the other side, the lower expressed control sample (76.4 AU) possessed more whitish-gray pixels thus higher IntDen values. This kind of variation in IntDen values between high and low gene expression samples is similar to $\mathrm{CP}$ values pattern in a real-time PCR system. It is well known that genes with upregulated expression levels (more abundant mRNA) have lower $\mathrm{CP}$ values compared to low-expressed samples that have higher CP values [13]. Therefore, the IntDen value is assumed to be a reliable substitute for the $\mathrm{CP}$ value in real-time PCR mathematical models. Gel express method facilitates quantifying gene relative expression using realtime PCR mathematical model yet with determinants derived from conventional PCR assay, i.e., IntDen values.

The mathematical model developed by [13] was adopted in this study for calculating the relative expression ratio. Equally important, $2^{-\Delta \Delta C t}$ method is also a widely accepted mathematical strategy for analyzing quantitative gene expression data [21]. Nevertheless, it relied on the hypothetical assumption that the 


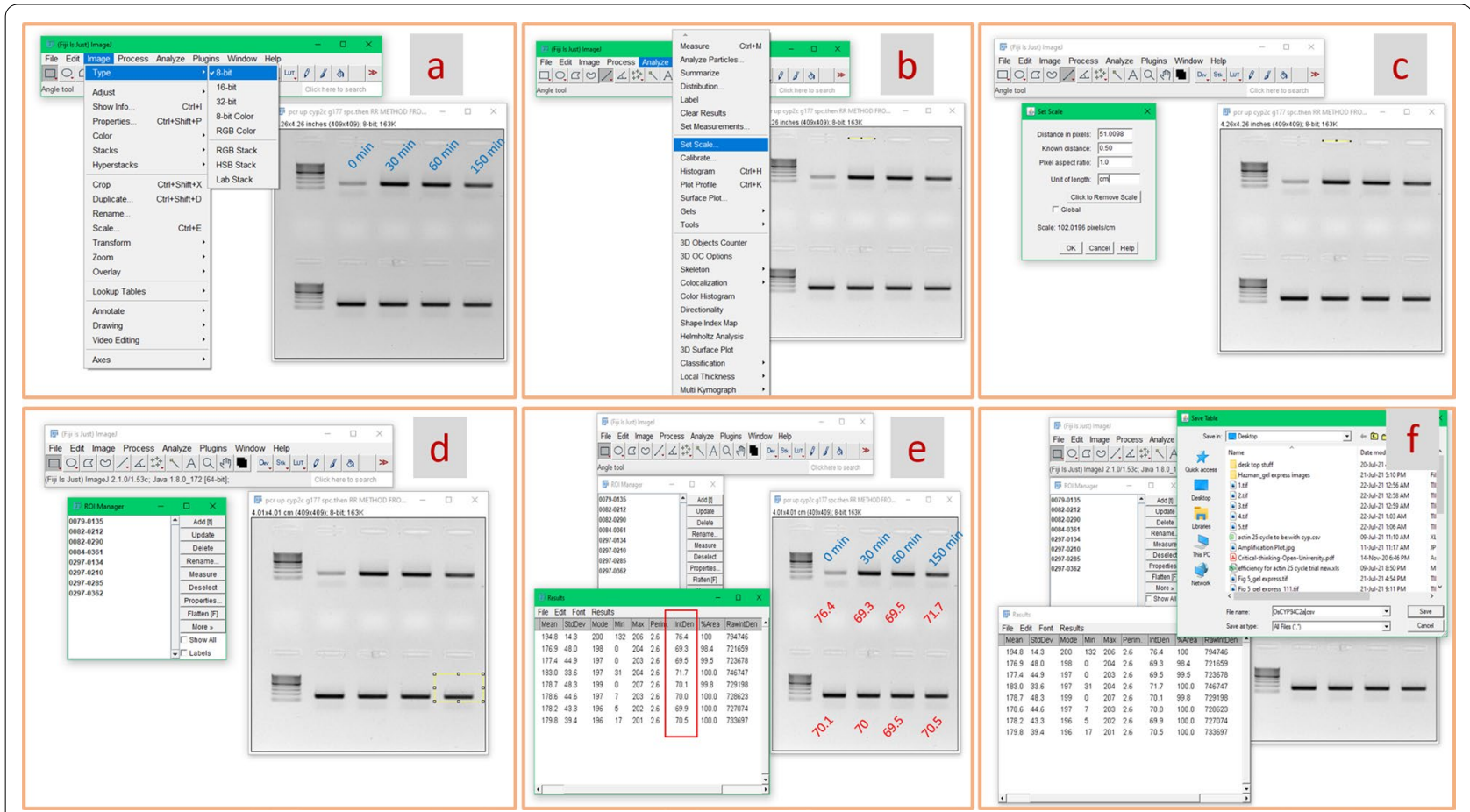

Fig. 5 Photographed-steps protocol of gel express method for attaining integrated densities (IntDen) values of PCR amplicon bands from agarose gel inverted-color image. The presented example illustrates quantifying OsCYP94C2a expression in response to mechanical wounding stress after 0, 30, 60 and 150 min in rice seedlings. The software used was the freeware ImageJ. a opening image by ImageJ software and changing its type to 8-bite grayscale, $\mathbf{b}$ and $\mathbf{c}$ illustrating scaling image depending on agarose gel well width (in this study it was $0.5 \mathrm{~cm}$ ), $\mathbf{d}$ selecting the area around the band of interest, preferably as shown in the example, then press " $\mathrm{t}$ " to open ORI manager, e after selecting all bands then click "measure" button in ROI manager, and $\mathbf{f}$ illustrated saving raw data as CSV file

efficiency of a real-time PCR reaction $E$ is $100 \%(E=2)$ for all examined samples and tested genes [22]. In this work, however, $E$ values for OsCYP94C2a, OsLOX8, and actin genes were experimentally calculated by setting up suitable standard curves using the formulas $E=2^{[-1 /}$ slope] and Efficiency percentage $(\%)=(E-1) * 100$. PCR amplification efficiency that is calculated with gel express method for all genes was in the accepted range $(\approx 60$ to $110 \%$ ) [23]. In OsCYP94C2a genes with a 25 cycle PCR program, $E$ values were 1.73 (98\% and $73 \%$ ). While in the case of OsLOX8 genes with a 33 cycle PCR program, $E$ values were 1.7 (117\% and 70\%). Interestingly, although the number of cycles was different, $E$ values for conventional PCR reactions with both target genes were almost the same (1.73 and 1.7). Empirical data supported that most accepted $E$ values should not be lower than 1.65 otherwise PCR reaction would be considered as failed [24]. The higher PCR efficiency $(>100 \%$ or $E>2)$ is an undesired parameter also; it is probably due to the presence of PCR inhibitors in highly concentrated samples [25].

OsCYP94c2a and OsLOX8 target genes represent two different responsive expression styles, fluctuating and accumulating, respectively. This allowed a satisfactory evaluation for gel express method under two different styles of gene expression patterns compared to real-time PCR assay. For actualizing gel express results, gene expression patterns were compared to real-time PCR at four different time points $(0,30,60$, and $150 \mathrm{~min}$ after wounding). OsCYP94c2a expression profile was previously studied in rice and found to fluctuate in response to wounding [26]. In case of OsCYP94C2a, regression analysis confirmed that gel express method is reliable and considered highly comparable to realtime PCR $\left(\mathrm{R}^{2}=0.9975\right.$, Fig. 3C). OsLOX8 (homolog to LOX2 in Arabidopsis) encodes the chloroplast precursor (EC 1.13.11.12) which is a member of the 13-lipoxygenases gene family in rice with herbivore-induced defense response $[27,28]$. OsLOX8 expression pattern was linearly accumulative, i.e., the level of mRNA abundance is getting higher over time (Fig. 4b, d). Similar to OsCYP94C2a, OsLOX8 expression pattern calculated by gel express was highly associated with real-time PCR $\left(R^{2}\right.$ equals 0.9976).

Obviously, the absolute numerical values of relative expression ratios for each time point were not identical in 
both investigated PCR methods and in either target gene. Nevertheless, the high $R^{2}$ values in regression analysis (Figs. 3c and 4c) are referring to the high level of association between gel express and real-time PCR assay. Unsurprisingly, absolute values derived from the gel express method were different from the values revealed by used real-time PCR system. [29] reported that gene expression values can significantly vary even with different realtime PCR systems. Furthermore, some readily detected genes using a real-time PCR system were completely undetected using another different one. Clearly, both gel express and real-time PCR strategies adopted different detection parameters and thus produced different absolute values yet both provided highly comparable dynamic expression patterns. For accuracy, gel express method could detect an amplitude level of nearly two in OsLOX8 gene expression at $30 \mathrm{~min}$ after wounding (Fig. $4 \mathrm{~b}$ ). This implies a considerable sensitivity for integrated density as a reliable measuring parameter for the quantification of gene expression.

Optionally, integrated density (IntDen) could be also utilized with raw gel images (blackish background/ whitish bands) to estimate integrated cycle (IntCyc). In this study, IntCyc refers to the number of cycles for gel express method (29 cycles, Fig. 1a). IntCyc improves the visualization differences between PCR amplicon bands under different treatments, thus better biological comparison. Therefore, it is recommended to consider 29 cycles as the initial default number of cycle in gel express method with target and reference genes. The relative expression ratio could be calculated easier with no need to prepare time-consuming and technically complicated efficiency $(E)$ calibration curves in case $E$ is hypothetically assumed to be $2(E=2)$. This could be attained by either using gel express IntDen values in replace of $\mathrm{Ct}$ (cycle threshold) in delta-delta $\mathrm{Ct}$ formula developed by [21] using the following equation: $2^{\Delta \Delta \text { IntDen }}$ or in the equation originally developed by [13]:

$$
\begin{aligned}
& {\left[2^{\text {IntDen(ref) }} / 2^{\text {IntDen(target) }}\right]_{\text {sample }}} \\
& \div\left[2^{\text {IntDen(ref) }} / 2^{\text {IntDen(target) }}\right]_{\text {control }}
\end{aligned}
$$

\section{Conclusions}

The extremely high cost of the real-time PCR system, qPCR instrument in particular, is and will remain the most challenging factor that hinders analyzing quantitative gene expression data in limited budget research institutes. Therefore, the presented work addressed this problem by suggesting a novel, cost-effective and reliable method, named here gel express, to quantify gene relative expression in conventional PCR system yet using real-time PCR mathematical models. Gel express method encompasses two main novel steps: (1) measuring integrated density (IntDen) values of PCR amplicon bands in agarose gel images using the free software ImageJ (see Fig. 5 for detailed photographed-steps protocol) and (2) using IntDen value for each PCR band as an alternative to crossing point $(\mathrm{CP})$ in equation developed by [13] to calculate gene relative expression ratios. Compared to data derived from the well-acknowledged real-time RTPCR, gel express is thought to be a doable, fast and costeffective method for achieving high-quality quantitative gene relative expression measurements using conventional RT-PCR.

\section{Abbreviations}

CDNA: Complementary DNA; CP: Crossing point; E: PCR amplification efficiency; IntCyc: Integrated cycle; IntDen: Integrated density; OsCYP94C2a: Cytochrome P450 of the subfamily CYP94 subclade C member 2a; OsLOX8:

Lipoxygenase8; RT-PCR: Reverse transcription polymerase chain reaction.

\section{Acknowledgements \\ The Author is grateful to Prof. Dr. Shireen Assem (Vice-president of Agricul- tural Research Center, Giza, Egypt) for facilitating the use of the real-time PCR system. The Author thanks Prof. Dr. Emad Anis, Director of AGERI, for his kind support. The author is thankful to Dr. Farida Kabil (Faculty of Agriculture, Cairo University, Egypt) for efficient discussions and great support. The author appreciates helpful scientific technical assistance provided by Ms. Shrouk Abd Elhamid (AGERI, Giza, Egypt).}

\section{Authors' contributions}

$\mathrm{MH}$ is the only author of this work. MH designed and conducted the experiments, performed the measurements, analyzed the data and wrote the manuscript. The author read and approved the final manuscript.

\section{Funding}

Not applicable.

Availability of data and materials

The datasets used and/or analyzed during the current study are available from the corresponding author on reasonable request.

\section{Declarations}

Ethics approval and consent to participate

Not applicable.

Consent for publication

Not applicable.

Competing interests

The authors declare there is no competing interests.

Received: 17 September 2021 Accepted: 4 January 2022

Published online: 15 January 2022

\footnotetext{
References

1. Chung DDW, Roch LKG (2013) Genome-wide analysis of gene expression. In: Lennarz WJ, Lane MD (eds) Encyclopedia of biological chemistry, 2nd edn. Academic Press. https://doi.org/10.1016/B978-0-12-378630-2. 00634-4

2. Parker RM, Barnes NM (1999) mRNA: detection by in situ and northern hybridization. Methods Mol Biol 106:247-283
} 
3. Hod Y (1992) A simplified ribonuclease protection assay. Biotechniques 13:852-854

4. Saccomanno CF, Bordonaro M, Chen JS, Nordstrom JL (1992) A faster ribonuclease protection assay. Biotechniques 13:846-850

5. Weis JH, Tan SS, Martin BK, Wittwer CT (1992) Detection of rare mRNAs via quantitative RT-PCR. Trends Genet 8:263-264

6. Rao MS, Van Vleet TR, Ciurlionis R, Buck WR, Mittelstadt SW, BlommeEAG LMJL (2019) Comparison of RNA-Seq and microarray gene expression platforms for the toxicogenomic evaluation of liver from short-term rat toxicity studies. Front Genet 10(1):1-16. https://doi.org/10.3389/fgene. 2018.00636

7. Etienne W, Meyer MH, Peppers J, Meyer RA (2004) Comparison of mRNA gene expression by RT-PCR and DNA microarray. Biotechniques 36(4):618-626. https://doi.org/10.2144/04364st02

8. Wu DY, Ugozzoli L, Pal BK, Qian J, Wallace RB (1991) The effect of temperature and oligonucleotide primer length on the specificity and efficiency of amplification by the polymerase chain reaction. DNA Cell Biol 10:233-238

9. Bustin SA (2000) Absolute quantification of mRNA using real-time reverse transcription polymerase chain reaction assays. JME 25:169-193

10. Sanhueza D, Vizoso P, Balic I, Campos-Vargas R, Meneses C (2015) Transcriptomic analysis of fruit stored under cold conditions using controlled atmosphere in Prunus persica cv. "Red Pearl." Front Plant Sci. https://doi. org/10.3389/fpls.2015.00788

11. Ginzinger DG (2002) Gene quantification using real-time quantitative PCR: an emerging technology its the mainstream. Exp Hematol 30:503-512

12. Hazman M, Hause B, Eiche E, Nick P, Riemann M (2015) Increased tolerance to salt stress in OPDA-deficient rice ALLENE OXIDE CYCLASE mutants is linked to an increased ROS-scavenging activity. J Exp Bot 66(11):3339-3352. https://doi.org/10.1093/jxb/erv142

13. Pfaffl MW (2001) A new mathematical model for relative quantification in real-time RT-PCR. Nucleic Acids Res 29(9):E45. https://doi.org/10.1093/ nar/29.9.e45

14. Wang AM, Doyle MV, Mark DF (1989) Quantitation of mRNA by the polymerase chain reaction. Proc Natl Acad Sci 86:9717-9721

15. Alnamoly MH, Alzohairy AM, El-Henawy IM (2020) EGBIOIMAGE: a software tool for gel images analysis and hierarchical clustering. IEEE Access 8:10768-10781. https://doi.org/10.1109/ACCESS.2019.2962319

16. Ahmed NE (2021) EgyGene GelAnalyzer4: a powerful image analysis software for one-dimensional gel electrophoresis. J Genet Eng Biotechnol. https://doi.org/10.1186/s43141-020-00114-X

17. Bradford WD, Cahoon L, Freel SR, Hoopes LLM, Eckdahl TT (2005) An inexpensive gel electrophoresis-based polymerase chain reaction method for quantifying mRNA levels. Cell Biol Educ 4:157-168. https://doi.org/10. 1187/cbe.04-09-0051

18. Breljak D, Ambriović-Ristov A, Kapitanović S, Čačev T, Gabrilovac J (2005) Comparison of three RT-PCR based methods for relative quantification of mRNA. Food Technol Biotechnol 43(4):379-388

19. Yamasaki Y, Komoike Y, Higashinakagawa T (2006) Adaptive changes in TEF-1 gene expression during cold acclimation in the medaka. Zoolog Sci 23(10):903-908. https://doi.org/10.2108/zsj.23.903

20. Ismail A, Riemann M, Nick P (2012) The jasmonate pathway mediates salt tolerance in grapevines. J Exp Bot 63(5):2127-2139. https://doi.org/10. 1093/jxb/err426

21. Livak KJ, Schmittgen TD (2001) Analysis of relative gene expression data using real-time quantitative $P C R$ and the $2-\triangle \triangle C T$ method. Methods 25(4):402-408. https://doi.org/10.1006/meth.2001.1262

22. Rao X, Huang X, Zhou Z, Lin X (2013) An improvement of the $2^{\wedge}$ (-delta delta $(T)$ method for quantitative real-time polymerase chain reaction data analysis. Biostat Bioinform Biomath 3(3):71-85

23. Pfaffl MW (2004) Quantification strategies in real-time PCR. In: Bustin SA (ed) The real-time PCR encyclopedia A-Z of PCR. International University Line, La Jolla

24. Mallona I, Weiss J, Marcos EC (2011) PcrEfficiency: a web tool for PCR amplification efficiency prediction. BMC Bioinform. https://doi.org/10. 1186/1471-2105-12-404

25. Svec D, Tichopad A, Novosadova V, Pfaffl MW, Kubista M (2015) How good is a PCR efficiency estimate: recommendations for precise and robust qPCR efficiency assessments. Biomol Detect Quantif 3:9-16. https://doi. org/10.1016/j.bdq.2015.01.005
26. Hazman M, Sühnel M, Schäfer S et al (2019) Characterization of jasmonoyl-isoleucine (JA-lle) hormonal catabolic pathways in rice upon wounding and salt stress. Rice. https://doi.org/10.1186/ s12284-019-0303-0

27. Wang R, Shen W, Liu L, Jiang L, Liu Y, Su N, Wan J (2008) A novel lipoxygenase gene from developing rice seeds confers dual position specificity and responds to wounding and insect attack. Plant Mol Biol 66(4):401414. https://doi.org/10.1007/s11103-007-9278-0

28. Umate $P$ (2011) (2011) Genome-wide analysis of lipoxygenase gene family in arabidopsis and rice. Plant Signal Behav 6(3):335-338. https://doi. org/10.4161/psb.6.3.13546

29. Lu S, Smith AP, Moore D, Lee NM (2010) Different real-time PCR systems yield different gene expression values. Mol Cell Probes 24(5):315-320. https://doi.org/10.1016/j.mcp.2010.04.002

\section{Publisher's Note}

Springer Nature remains neutral with regard to jurisdictional claims in published maps and institutional affiliations.

\section{Submit your manuscript to a SpringerOpen ${ }^{\circ}$ journal and benefit from:}

- Convenient online submission

- Rigorous peer review

- Open access: articles freely available online

- High visibility within the field

- Retaining the copyright to your article

Submit your next manuscript at $\boldsymbol{\nabla}$ springeropen.com 